\title{
Digital Interactive Television in the UK: is the opportunity for 'inclusivity' being missed?
}

\author{
Alex Carmichael, Mark Rice and David Sloan \\ Applied Computing, University of Dundee \\ Dundee, DD1 4HN, UK \\ \{acarmichael, mrice, dsloan\}@computing.dundee.ac.uk
}

\begin{abstract}
The switchover to digital television (DTV) will bring about an expansion of entertainment and information services available via the TV, and in doing so fundamentally changes traditional concepts of household viewing. From a UK perspective, the technological infrastructure of DTV has the potential to foster the social inclusion of vulnerable groups, such as disabled and elderly people, by improving their ability to receive enhanced access to content and other services available via this expanding medium. Yet, despite encouragement from a variety of stakeholders who recognise this opportunity (and the challenges along the way), and given the responsibilities of the regulatory body Ofcom under the terms of The Communications Act, progress so far has been disappointing. Far from increasing access for these vulnerable groups, there is a significant risk of increasing their marginalisation and disfranchisement, partly because DTV equipment is inherently more complex to operate than is analogue, but mainly because steps have not been taken to ensure that consideration is given to the wide diversity of abilities within the viewing population for the design of DTV equipment and services. This paper describes some of the fundamental issues that are stifling progress toward universal access in the development of DTV, and in doing so illustrates some of the barriers to this new infrastructure being an inclusive success.
\end{abstract}

Digital Television, Ofcom, legislation, inclusive design.

\section{INTRODUCTION}

Television plays an important role in most people's lives, bringing entertainment and information into people's living rooms at the press of a button, and providing a conduit into the home for a wide range of images and sound. The current move toward digital television (DTV), and the associated 'interactivity' that additional current and potential services can provide - be that 'personalizing' TV schedules, accessing health information, voting, or ordering pizza - seems likely to increase the importance of the role television plays for many, and will also raise some very important issues related to the impact television has on peoples lives [1].

It has been claimed that "the UK is the world leader in digital television with the highest take-up in the world twice the European average" [11]. From a perspective of inclusion and accessibility, there have been promises from the Government that, as the UK moves toward a switchover from analogue to digital television, "viewers can be assured that their interests, particularly those of the most vulnerable, will be at the heart of every decision we make" [7]. Statements such as this, made against a background of UK legislation such as the Disability Discrimination Act (1995) and The Communications Act (2003), suggest that the emergence of DTV should be accompanied by a wealth of research aimed at ensuring the broadest range of people can gain the maximum benefits that this new technological infrastructure can provide. Perhaps central to this is Section 10 of the Communications Act which, in establishing the regulatory body for the communications industry (Ofcom) states;

(1) It shall be the duty of OFCOM to take such steps, and to enter into such arrangements, as appear to them calculated to encourage others to secure-

(a) that domestic electronic communications apparatus is developed which is capable of being used with ease, and without modification, by the widest possible range of individuals (including those with disabilities); and

(b) that domestic electronic communications apparatus which is capable of being so used is as widely available as possible for acquisition by those wishing to use it. 
However, despite this and other similar claims from Government departments and Ofcom, it would appear that with regard to usability and accessibility for many older and disabled people, the reality of the emerging situation falls markedly short of this 'inclusive' approach. This is of particular concern given the range of powerful influences pushing for switchover to be completed sooner rather than later [9].

This paper will present a brief overview of the current DTV situation in the UK followed by a description of the main driving forces emerging from the commercial and government entities involved. Subsequent sections will identify some of the main 'lessons' that are available regarding the introduction of earlier interactive technologies which failed to take into consideration the importance of usability and accessibility. These 'lessons' relate to earlier incarnations of interactive television, the development of the World Wide Web and the wealth of relevant information made available by a wide range of research. This will be followed by an indication of the current state of affairs, wherein it appears that these lessons are being ignored, and this will be followed by some concluding comments.

\section{DIGITAL TELEVISION IN THE UK: AN OVERVIEW}

Currently, digital television is available on four platforms in the UK; cable, satellite, terrestrial and ADSL (broadband). Each of these uses different transmission methods, and as a result, each demonstrates different strengths and weaknesses regarding levels of interaction, usability and accessibility.

One aspect of interactivity can be characterised as 'enhanced programming' - using the extra bandwidth of digital to transmit additional content, such as overlays, text and graphics, available to the user via their remote control (colloquially, in the UK, by 'pressing the red button'). Some limited interaction is supported on most platforms, but fuller engagement requires some form of return path either integrated with, or additional to, the system.

There are also interactive services, including gaming, betting, and shopping channels, which require a 'full' return path for individual identity authentication, to allow viewers to purchase goods, request information, etc. Limited interactive services can be provided without a full return path but this requires that the interactive functionality and related content be 'downloaded' to the local reception equipment. Currently the most common form of this is the Electronic Programme Guide (EPG), which is central to the user finding and utilising the programmes and services available (including 'accessibility features'), and as such is critical to the usability of the system.

The addition of such interactive functionality represents the most fundamental change that digital television introduces, as it affects - and potentially erodes - the familiar and trusted status of television. An illustrative example of this is the very low uptake of certain interactive services, such as email and interactive shopping channels, indicating that the providers did not build on viewers' expectations and understanding of television as primarily a source of entertainment associated with other family related activities which tend to occur in front of the TV screen [16]. Nevertheless, the push to encourage viewers to treat television increasingly as a 'lean forward' activity makes TV viewing significantly more like usage of a personal computer (PC). However, in comparison to the PC, DTV is technically, operationally and socially distinct. For example:

- Digital STBs have limited memory and processing power, and 'closed' operating systems. Input is generally limited to the remote control handset as distinct from a full keyboard and/or mouse or other, possibly more appropriate, input devices.

- Commercial assistive technologies, available for PCs, do not exist for DTV equipment.

- 'Traditional' television screens generally have a lower resolution compared to computer monitors.

- Viewing distances are substantially greater and more laterally variable when watching television then when operating a PC.

Television is socially engrained as a part of family life - consider the typical family room with the TV set as a focal point. The social experience of 'just watching TV', often involves a complex negotiation of rights, routines and values between family members, who all bring their own 'dynamics and politics' to the household. Other aspects of television viewing also make it fundamentally different from PC use. For example, the 'leisure' context of TV means that the associated human activities are very different from the "distinct goals to be achieved as is the case with many activities in working life" ([14] p. 5). Furthermore, while watching programmes through analogue television is a simple task, with DTV, even if someone 'only wants to watch telly' they need to be able to navigate 
through a detailed menu-based EPG in order to find out what they want to watch. This can be problematic for many of the wider population, and is exacerbated particularly for many older and disabled people.

\section{GOVERNMENT AND COMMERCIAL DRIVERS}

In addition to the technological and social changes related to DTV, the move toward 'digital switchover' is being led by commercial and governmental interests From a commercial perspective, the move toward digital offers the potential of an enormous market for new equipment and services, and presents opportunities to increase subscription numbers (for certain broadcast platforms) and generate other highly lucrative revenue streams. Unprecedented levels of marketing related information about individual customers and households will also become available. These and related 'alternative' marketing techniques seem set to increase given the emerging challenges for 'traditional' television advertising. For example, the Personal Video Recorder (PVR), marketed as allowing audiences to record and store large quantities of programmes, but also allowing options (which many are apparently taking) to avoid adverts and otherwise 'break away' from centralised broadcast schedules [13]. Although these developments can give viewers more control they may also be less beneficial in the longer term, if the uncertainties raised over future advertising revenue mean that this new infrastructure, already unfamiliar to many people, will remain relatively unstable for the foreseeable future.

The UK Government also has an interest in the revenue available from the increased bandwidth that analogue switch-off will provide. For this and other reasons it identifies DTV as the favoured means of delivering various 'eGovernment' services, particularly for people who are reluctant or unable to use a PC [23]. A number of such initiatives have been launched, such as NHS TV, launched in 2004 to provide information on local services (GPs, dentists, and pharmacies), advice on healthy living, treatment on common health problems and e-booking [19]. The National DigiTV Project involves providing 'starter kits' for local authorities to offer e-services across DTV platforms, to improve community development [8]. Accessibility and ease of use are obviously critical to these services yet, while the provision of these services on-line may be cost-effective, they will inevitably reduce the availability of face-to-face contact between providers and recipients. This is of concern due to the significant numbers of people who already depend on intermediaries to cope with the complexities of interactions such as claiming income support, and who also tend to face the greatest barriers in taking up DTV generally [17], not least of which being the difficulty of using the DTV system itself. It is unclear how on-line systems will accommodate these variable personal support mechanisms and offer suitable levels of 'on-line' support to these particularly vulnerable people.

\section{LESSONS FROM EARLIER INTERACTIVE TV}

An important element in the development of DTV is an apparent failure by these main stakeholders to learn lessons from previous analogous developments, both in earlier implementations of 'interactive' television which were far from successful, and in the evolution of the World Wide Web, which despite more recent progress, still presents significant usability and accessibility barriers to many people.

For over 30 years broadcasters and designers have investigated ways to extend television's potential as a domestic information and communication device. In the UK this started with the development of on-screen text displayed for hearing impaired viewers, which then developed into broader information services (e.g. Teletext). In the United States, equivalent first generation systems included Viewtron, which adopted a more 'graphic' version of Teletext called Videotex. Despite being marketed as a user-friendly technology, particularly for those without PC experience, in less than three years of commercial availability it failed, due (amongst other factors) to a lack of consumer demand. This was similar to the "dozens of media and telecommunication companies, as well as governments around the world, [who] collectively poured hundreds of millions of dollars into the development and marketing of Videotex services only to be frustrated by a persistent lack of enthusiasm from consumers" ([15] p. 139), and although initial 'take-up' seemed promising, "only 4 out of 10 customers...continued to subscribe after six months" ([15] p. 154) - which contributed ultimately to the failure of the service.

Similarly, during the same period, other interactive systems were developed such as Qube, launched by Warner Communications and Amex Cable. Unlike any of its contemporaries Qube offered a number of basic two-way interaction services, allowing cable subscribers to select pay-per-view movies and access interactive content through education or talk show programmes. However, despite early commercial optimism, only about 20 percent of subscribers were using the interactive services available. Low participation was linked specifically to the lack of 
true interactivity available ([15] p. 161). Interactive systems such as Qube and Viewtron demonstrate significant 'user-centred' mistakes, in that they were developed with seemingly limited knowledge of audience behaviour in using such applications, both in terms of usability and in regard to its disruption of 'TV viewing' as the familiar status-quo. Further, they illustrate the necessity to invest sufficient time and resources on the needs, preferences and desires of potential customers, rather than simply persuading them to invest in it on the grounds of dubious marketing hyperbole. This is of particular importance in the present UK situation as analogue switch-off disallows any dissatisfied customers simply reverting to their original service.

\section{LESSONS FROM THE DEVELOPMENT OF THE WWW}

Tim Berners-Lee famously noted that for the World Wide Web, "access by everyone regardless of disability is an essential aspect" [26], the reality has been widespread digital exclusion as web technologies and design techniques evolved without due consideration of the specific access needs of people with reduced sensory, mobility and cognitive capabilities. There has, though, been a noticeable increase in prominence of the issue of web accessibility, driven by a rising awareness of legal obligations of on-line content providers to avoid unjustified discrimination against disabled people expressed in legislation such as the UK's DDA and the amended Section 508 of the Rehabilitation Act in the US.

Amongst web content authors, awareness of guidelines for accessibility, in particular the W3C Web Content Accessibility Guidelines (WCAG) [27] has never been higher, although levels of site accessibility and usability remain disappointing, as reported by the Disability Rights Commission [10]. While arguments for the economic benefits of web accessibility are making progress, practical stumbling blocks remain. In particular, subjective application of guidelines (e.g. the provision of text alternatives for images requires the text to be appropriate for the page concerned) requires new skills be learned. In other cases, recommended techniques for accessible design have themselves become problematic, where due to the diverse and unregulated development of web browsers, some guidelines are difficult for content developers to apply in practice. These and related problems have become so difficult to solve because they were only tackled after the commercial and technological infrastructure was in place, and unless action is taken now it seems likely that a similar fate is in store for accessible DTV.

However, where legislation directly affects web technology and software providers, arguably more significant progress has been made. Since the introduction of Section 508, which covers the provision of IT by and for US federal agencies, there has been a remarkable increase in the attention paid to accessibility by those companies who either wish federal agencies to use their data formats or authoring software. Here, the nature of accessibility legislation is such that those who choose to follow it gain commercial benefit, by having a particular market made available to them, whereas most disability discrimination legislation appears to focus only on the punitive impact on those who do not comply [9]. Despite this, awareness of the potential commercial benefits of a more 'inclusive design' approach is still very limited among commercial stakeholders.

The introduction of guidelines and voluntary standards for the web has had a lower than hoped-for impact mainly because there is no overarching authority to 'enforce' them. Although Ofcom has effectively been granted such an authority with regard to DTV in the UK, it seems unwilling to take on this responsibility (declaring itself a "lighttouch" regulator) which raises the fear that it's various proposed voluntary codes and guidelines are likely to be equally ineffective.

\section{RELEVANT RESEARCH}

Given Government claims over the importance of accessibility and usability of DTV (and of ICT more generally), it is somewhat surprising that much relevant research appears either to be dismissed or ignored by the commercial and Government stakeholders driving the switch to digital. Work from a variety of domains has described one general phenomenon that indicates the importance of ensuring ease of use to the broad range of abilities in the public. That is, many people, and particularly older people, often tend to blame themselves for the problems encountered when faced with difficulties caused by poor interface design, (Reason, cited [25]). This is important as it introduces a major bias into the nature of 'customer feedback'. Many of the problems encountered by older or disabled people when accessing a service, or indeed anyone at the steeper end of the associated 'learning curve', tend not to get fed back to the 'service provider'. Feedback is most likely to be forthcoming about the 'problems' encountered by users more capable of identifying and articulating what they consider is wrong with the 
interface - users who are most often 'early adopters', asking for more features and functionality. Thus, while it may serve other commercial purposes, a policy of listening to one's customers will not necessarily provide adequate information to produce a more 'inclusive' product. Other approaches must therefore be adopted to find out what potential customers need and want.

Adequate coverage of all the relevant findings in this area is beyond the scope of the present paper, although disciplines such as media studies, ethnography and human factors and others provide a variety of information that is both generally and more specifically relevant to issues such as perceived acceptability, provision of accessibility features and accessibility and usability more generally. The following sections will address some of these.

While not exhaustive, the following list identifies some of the currently unresolved issues of acceptability, which include:

- Trust - or lack of it, identified through concerns over hidden running costs, line rental and service fees [21] and costs of return path options [24].

- Security - apprehension and misunderstanding about the privacy of personal identification numbers (PIN) [21] and credit card details sent to commercial operators [24].

- Complexity - the impact of cross media formats and 'universal' devices evolving to support greater interactivity and presenting audiences with much more functionality to deal with, which is closely related to...

- Compatibility - of (multiple) STBs (and other home entertainment technology) to integrate into the 'practices and social arrangements' that are found in domestic environments [21].

- Interactivity - the numbers of viewers who actually explore and 'make sense' of the types of services available seem low, as studies suggest many are baffled, hostile or disappointed. [24].

- Individual vs. group interaction - the possibilities of services or applications to enhance sociability within group situations, instead of interactivity that currently limits engagement to individual activities [3].

\section{ACCESSIBILITY, USABILITY AND DTV: WHERE ARE WE AND WHERE SHOULD WE BE?}

In addition to the widely documented benefits, actual or potential of DTV to the population, the technology offers significant potential over analogue television for the provision of accessibility features for people with sensory, motor and cognitive impairments. With DTV, the extra bandwidth allows efficient delivery of these accessibility features along with each programme. At the same time, the increased complexity both of the information and communication space to which DTV enables access, and the interactions required to carry out even basic tasks like choosing a particular television channel to watch, impacts directly on usability, and without careful design, usability problems may be magnified for people with specific access needs.

\subsection{Accessibility}

Accessibility features necessary to ensure optimal accessibility of DTV services can be classified into one of two types, referred to here as, 'Classic' accessibility features (related to TV viewing), and those accessibility features more related to the interaction inherent in the use of DTV.

\subsection{1 'Classic' Accessibility Features}

Classic accessibility features we define as those features that would be commonly recognised by broadcasters and regulators, and many of which would even be familiar to many viewers beyond those with impairments for whom they directly benefit. The 'classic' set of accessibility features would include:

- Captions: the provision of on-screen text alternatives for spoken and other important non-spoken sound information, provided for people who are deaf or hard or hearing, or otherwise have difficulty hearing the broadcast sound (and therefore widely used when the TV is in a noisy environment such as a bar).

- Audio description: additional spoken audio, delivered at appropriate times during quiet periods of the programme's soundtrack, delivering essential descriptive information to aid understanding for people who have difficulty seeing, or cannot see, the screen. 
- Subtitles ${ }^{1}$ : the provision of on-screen text alternatives, translating the spoken content into another language - an accessibility solution for those whose first language is not that of the broadcast content.

- Signing: the provision of a real-time signed translation of the spoken content- again, an accessibility solution for those whose first language is not that of the broadcast content, but likely to be almost exclusively people who are deaf.

With the exception of subtitles, the above accessibility solutions compensate primarily for sensory impairments. In order for a user to access them, three key steps must be met:

- The accessibility solution must be provided by the broadcaster;

- The viewer must be able to identify which programmes contain access features;

- The STB and remote control must facilitate the easy utilisation of these features.

At the time of writing, of the 'classic' accessibility features, the provision of captions is widespread for analogue and digital television in the UK, signing and audio description significantly less so. Each is generally recognised to varying levels both by broadcasters as services that should be provided for at least a proportion of programmes, and by technology manufacturers as features that should be supported by STB technology. Indeed, Ofcom, in its capacity as a regulator of UK broadcast media, has produced draft codes of practice for the provision of captions and audio descriptions, although these have received some criticism, particularly in that they appear to be broadcaster rather than consumer-driven, concentrating more on ensuring that upper limits of both programme output and financial outlay are defined, rather than minimum targets to be met by broadcasters [4].

\subsubsection{Other accessibility features}

Perhaps less visible or well recognised, but equally important to ensuring an accessible and equitable DTV service are other accessibility features. These include:

- Audio-enabled EPG: to enable people unable to see the screen due to visual impairment to effectively and independently choose their preferred viewing schedule (including the identification of 'accessible' programmes) and navigate the information space that is a DTV service, the on-screen EPG must be presented in audio format, and be understandable and navigable without vision. At present, such systems exist only in research laboratories. (If implemented, such an approach could be considered by many 'unimpaired' people as easier to use than current 'GUI' EPGs).

- Display aspects, such as allowing viewers to tailor the appearance of on-screen text, for example changing size, colour or font; avoiding a reliance of colour to distinguish either remote control buttons or on-screen information.

- Easy-to-operate remote control: for many people with reduced cognitive processing ability, limited vision and/or manual dexterity the remote control is a significant barrier, not simply as the way in which DTV content and services must be accessed, but also as it may be the only means by which other DTV accessibility features may be enabled. The impact of this is discussed further in Section 7.2.

Unfortunately, it appears that these accessibility features have been given significantly less prominence by both commercial service providers and by Ofcom. Unlike captioning, audio description and signing, no comparable attention appears to have been paid to the need for an accessible EPG or accessible remote as a baseline requirement of a DTV service.

Another difficulty with respect to accessibility is that in the UK, many people have been persuaded to take up DTV through the low cost Freeview option - a limited functionality set top box available for a one-off purchase price with no subscription fee. This allows access to a subset of available digital terrestrial TV, without an integrated return path. In other words, viewers cannot send data back to the DTV service provider. Being low cost, Freeview is less capable of supporting the accessibility features that a more expensive system may (e.g. audio description). Thus accessibility is at risk of becoming an 'extra' rather than a standard feature of DTV.

\subsection{Usability of the interface}

\footnotetext{
${ }^{1}$ NB In the UK, the term "subtitles" is used to refer both to on-screen text that is a translation of (foreign language) spoken content, and to text representing spoken and non-spoken audio content for deaf and hard of hearing viewers. The latter is known as "captions" virtually everywhere else in the world.
} 
Beyond those who require accessibility features described above, there are many people whose requirements have tended not to be considered in the design of software interfaces generally. Thus, many of the interaction techniques and elements which have been imported almost directly from PCs into DTV preserve this usability gap. Other aspects further worsen this state of affairs - for example, in many STB set-ups, some basic TV functions cannot be controlled by the DTV remote control, such as volume control. This type of problem is exacerbated if the viewer also has other equipment, such as a DVD or video player connected to their television, each with its own remote control.

DTV usability may also be affected for many people due to critical alterations in the associated mental model viewers will have developed with regard to analogue broadcasts. For example, text services (including captions) no longer function as a 'side channel' to the one being watched. Unlike analogue TV, where captions were effectively one 'page' of Teletext, utilising DTV captions may involve significant navigation, which can introduce further difficulty. A variety of research has indicated that this sort of 'unlearning/relearning' of a familiar, but often implicit, mental model is difficult, particularly for older people (e.g. [2]). Other general problem areas include:

- The remote control handset: These often incorporate excessive numbers of buttons, placed too closely together, with little meaningful grouping and often inadequate labelling. For many people, this may be a mild inconvenience; for others it can cause significant difficulty. These difficulties add to the basic 'ergonomic' problems of remote controls by presenting the viewer with effectively two related, but spatially separated, interfaces to deal with, which is problematic for many people but particularly for older people (e.g. [6]) or other people with visual or dexterity limitations.

- Dual Interface design: The problems caused by this dual interface situation are most apparent in the dynamic operations involved in an on-going interaction [2]. To illustrate, a viewer looks at the on-screen display which will either directly or indirectly provide information about the available operations, and thereby about which button(s) to press. Age-related changes to vision and cognition can combine to make this fairly straightforward procedure significantly more difficult. That is, changes to working memory and vision increase the possibility that, while attention is moved from the screen to the remote, the appropriate button's identity is forgotten before it is actually located, meaning the viewer must 'start again' by returning to the onscreen display. The difficulties of switching vision and attention between these two interface elements are further exacerbated for many older people who often require different corrective lenses for the two different viewing distances involved. The necessity of changing spectacles in this way adds to the time taken to switch from screen to remote control, and further increases the probability of forgetting and related problems.

- Navigation: Beyond the sheer quantity of buttons, the need to attend regularly to the remote control handset is also increased by the wide range of different ways that on-screen 'items' and other interaction operations are mapped onto handset buttons. In some cases, the mapping may be simple and direct, such as activating numbered list items with the appropriate numerical button. On the other hand, 'navigational' functions such as 'back (one step)' or 'back (to TV)' are inherently difficult to map unambiguously onto existing buttons [18]. This highlights another fundamental usability problem regarding the remote control handset, whereby the number of available functions far outstrips the number of available buttons, making these forms of uncertain mapping almost inevitable. This uncertainty is increased further because some functions are only available some of time, meaning that the system effectively works in different modes. This and other 'mode problems' are also known to significantly compromise usability [2].

Usability difficulties relating to the remote control are magnified by Ofcom's apparent unwillingness to enforce baseline standards for remote control design and functionality. Taken together, these issues suggest that significant effort is still required to make this new infrastructure accessible and usable, and thereby optimally beneficial to as many people as possible.

\section{CONCLUSIONS}

DTV, in terms of the technology and the services made available by the technology, offers enormous potential to reduce the exclusion faced by many groups, including disabled and elderly people; and research and development shows that enhanced accessibility of broadcast content is achievable. It is therefore of great concern 
that claims for an inclusive approach to the introduction of DTV do not seem to be reflected in recent developments in the UK. Of particular concern is that while Ofcom's Consumer Expert Group (CEG) produced a report on this issue which made many recommendations that would have addressed many of the problems outlined in the present paper [5], it appears that little attention has been paid to it thus far.

By contrast, a report by the Department of Trade and Industry (DTI) [12] does seem to have gained favour by policy-makers, even though (or perhaps because) it recommends what is effectively a 'do-nothing' approach. For example, it states: "we believe that innovation in digital television products will improve usability and reduce exclusion" on the grounds that "Many of the problems faced by those with some level of capability loss will be solved once usability is improved for the broader viewing population". The history of usability and accessibility of PCs and the WWW strongly suggests that this is a particularly ill-informed assumption ([20] pp. 74-87). The report also claims; "For comparable, everyday viewing we see no fundamental barriers to eventually achieving almost the same level of accessibility as analogue televisions" (emphasis added). Given the disruptive nature of this technological infrastructure (i.e. the requirement of analogue switch-off) and the fact that it is being imposed as a result of government policy rather than because of consumer demand, and also on the basis of the relevant legislation and of basic social responsibility, the authors feel that this is simply not good enough. It is to be hoped that accessibility plays more of a role in future developments in the UK, and that other countries at an earlier stage in the journey towards DTV adoption seize the opportunity to actively ensure that accessibility and usability more generally, is a core part of any baseline provision.

At the time of writing, another relevant report has come to the authors' attention, which will possibly help to push things in a more inclusive direction. That is, Ofcom's Consumer Panel (set up under Section 16(2) of the Communications Act as independent from Ofcom, but integral to its policy making, and not to be confused with the CEG, cited above) has produced a report [22] that clearly reiterates and supports many of the CEG report recommendations. This includes identifying the importance of "...widely available, basic, user-friendly equipment which provides 'easy-to-use' options for people who do not want and in fact are somewhat deterred by complex functionality." (p. 13), and the need to "...ensure that an accreditation system is in place which would enable 'good' designs to carry an endorsement or rating from an appropriate organisation. The DSO logo could also be used to help play this role" (Annex 4, 2). This report also suggests agreement with the present author's view that action is needed sooner rather than later. For example, the report states, "The Panel strongly recommends that equipment manufacturers and retailers take on board right now the need for user-friendly equipment and clear

labelling." (p. 13, emphasis added). It can be hoped that such calls for improved inclusivity will soon begin to have a positive impact of the role digital television can have in everybody's lives.

\section{REFERENCES}

[1] Brookes, M. (2004) Watching Alone: Social capital and public service broadcasting. The Work Foundation in partnership with the BBC, May 2004

[2] Carmichael, A. (1999) Style Guide for the design of interactive television services for elderly viewers. Independent Television Commission, Kings Worthy Court, Winchester. Available at http://www.computing.dundee.ac.uk/staff/acarmichael/Carmichael_DesignStyleGuide.pdf. Cited 2004

[3] Christesen L (2004) Out of interactive television. In: Proceedings of the 2nd European Conference on Interactive television: Enhancing the Experience, Brighton, UK, March-April 2004

[4] Clark J (2004) Response to Ofcom consultation on draft code providing television access services. http://www.ofcom.org.uk/consultations/responses/tv_access_services/responses/?a=87101. Cited 2004

[5] Consumer Expert Group (2004) Persuasion or compulsion? Consumers and analogue switch-off, available at; http://www.digitaltelevision.gov.uk/pdf_documents/publications/ Consumer_Expert_Group_report.pdf. Cited 2004

[6] Craik, FIM, Salthouse TA (2000) The Handbook of Aging and Cognition (2nd ed.). Mahwah, N.J.: Lawrence Erlbaum Associates 
[7] DCMS (2004) Broadcasting Minister statement, "Consumer Expert Report Into Digital Switchover Published". http://www.culture.gov.uk/global/press_notices/archive_2004/dcms114_04.htm. Cited 2004

[8] DigiTV project (2004) http://www.digitv.org.uk. Cited 2004

[9] DigiTV project (2004) The New Citizen Channel for the Digital Age: Delivering Local Government Services on Digital Interactive TV. http://www.digitv.org.uk/content_images/Digitv_finaldoc_tcm2-568.pdf. Cited 2004

[10] Disability Rights Commission (2004) The web: Access and inclusion for disabled people. TSO, London

[11] DTI (2004) Digital Television. http://www.dti.gov.uk/industries/broadcasting/digital_television.html. Cited 2004

[12] DTI/The Generics Group (2003) Digital Television for all: A report on usability and accessibility design. http://www.digitaltelevision.gov.uk/pdf_documents/publications/Digital_TV_for_all.pdf. Cited 2004

[13] Dureau V (2004) Addressable advertising on digital television. In: Proceedings of the 2nd European Conference on Interactive television: Enhancing the Experience, Brighton, UK, March-April 2004

[14] Eronen L (2003) User-centred research for interactive television. In: Proceedings of the 1st European Conference on Interactive television: From viewers to actors, Brighton, UK, April 2003

[15] Fidler R (1997) Mediamorphosis: Understanding new media. Sage Publication Ltd, London

[16] Gawinski M (2003) Interactive television production. Focal Press, London

[17] Irving A, Sparham I, Spicer N (2003) Attitudes towards electronic service delivery http://www.dfwp.gov.uk/asd/asd5/ih2003-2004//H117.pdf. Cited 2004

[18] Lessiter J, Freeman J, Davis R, Dumbreck A (2004) Understanding DTT remote control button labelling: a multi-method approach. Proceedings, Second European conference on Interactive Television, Brighton.

[19] NHS Direct: A new gateway to healthcare (2004)

http://www.nhsdirect.nhs.uk/misc/NHS\%20Direct\%20AR\%20FINAL.pdf. Cited 2004

20] Norman D, (1999) The Invisible Computer, The MIT Press, London

[21] O'Brien J, Rodden T, Rouncefield M, Hughes J (1999) At home with the technology: An ethnographic study of a set-top-box trail. ACM Transaction on Computer-Human Interaction 6 (3), pp 282-308

[22] Ofcom Consumer Panel (2004) Supporting the most vulnerable consumers through digital switchover. (November 2004), available at; http://www.ofcomconsumerpanel.org.uk/dso.htm

[23] Office of the E-envoy (2003) Digital Television. A policy framework for accessing e-government services. http://www.govtalk.gov.uk/documents/digital_tv.pdf. Cited 2004

[24] Pemberton L, Rice M, Griffiths, R (2004) Fear and loathing in the living room. Acceptability issues for interactive television services. In: proceedings for the 18th British $\mathrm{HCl}$ conference, Leeds Metropolitan University, September 2004

[25] Stanton N (1998) Human Factors in consumer products. Taylor and Francis, London

[26] Web Accessibility Initiative (2004) http://www.w3.org/WAI. Cited 2004

[27] Web Content Accessibility Guidelines 1.0 (1999) http://www.w3.org/TR/WCAG10 